\title{
Factors Influencing the Continuance Use of Mobile Social Media: The Effect of Privacy Concerns
}

\author{
Kwame Simpe Ofori ${ }^{1, *}$, Otu Larbi-Siaw ${ }^{1,2}$, Eli Fianu ${ }^{2}$, \\ Richard Eddie Gladjah ${ }^{3}$ and Ezer Osei Yeboah Boateng ${ }^{2}$ \\ ${ }^{1}$ SMC University, Switzerland \\ ${ }^{2}$ Ghana Technology University College, Ghana \\ ${ }^{3}$ Ho Polytechnic, Ghana \\ ${ }^{*}$ Corresponding Author: kwamesimpe@gmail.com
}

Received 31 August 2015; Accepted 20 November 2015; Publication 22 January 2016

\begin{abstract}
With over 800 million active Whatsapp users, Mobile Social Networks (MSNs) have become one of the most vital means of social interactions, such as forming relationships and sharing information, sharing personal experiences. The mass adoption of MSN raises concerns about privacy and the risk of losing one's personal information due to personal data shared online. This paper sought to examine the role of Privacy Concerns in the continuance use of Mobile Social Media. The Effects of factors such as Perceived Ease of Use, Perceived Usefulness and Perceived Risk and Perceived Enjoyments on Satisfaction and Continuance intention were also explored. Survey data was collected from 262 students in Ghana Technology University College and analysed using the Partial Least Square approach to Structural Equation Modelling with the use of SmartPLS software. Results from the analysis showed that Perceived Usefulness, Perceived Risk and Perceived Enjoyment were significant predictors of Satisfaction. Satisfaction in turn was found to be a significant predictor of Continuance Intention. Satisfaction also mediated the paths between Perceived Risk, Privacy Concern and Continuance Intention. The results are discussed and practical implications drawn.
\end{abstract}

Journal of Cyber Security, Vol. 4, 105-124.

doi: $10.13052 / \mathrm{jcsm} 2245-1439.426$

(c) 2016 River Publishers. All rights reserved. 
Keywords: Mobile Social Media Network, Privacy Concerns, Perceived Risk, Continuance Use.

\section{Introduction}

Mobile Social Media is fast becoming the number one medium for social interactions. This development is fuelled by the proliferation of mobile devices and the ever increasing $3 \mathrm{G}$ and $4 \mathrm{G}$ penetration. The mass adoption of this service presents some challenges with regards to privacy and the risk of losing one's personal information. Most Mobile Social Media Applications collect personal information such as user's demographics, preferences, and location from users. These information in the hands of wrong person could result in identity theft and other illegal use of such information. Privacy concerns could be a major reason why people do not adopt or discontinue after initial adoption.

Retaining users and facilitating their continuance use is essential to the success of any information system (Zhou \& Li, 2014). This is because the cost of acquiring new customers is about five times that of retaining old ones (Bhattacherjee, 2001; Spiller, Vlasic, \& Yetton, 2007; Vatanasombut, Igbaria, Stylianou, \& Rodgers, 2008). For service providers to be able to recoup the investment made installing and launching the service it is therefore important that users of the service do not discontinue after initial adoption. The mobile social media market is quite competitive as they offer similar services and features (Zhou \& Li, 2014). It is also quite easy for users to switch from one MSN to the other since a lot of the applications can be downloaded for free. The continuance usage by user therefore can be a source of competitive advantage for these service providers. Social media networks like hi5, MiSpace and Blackplanet which were unable to retain their users have lost out in this competitive arena. Despite the need to understand users' continuance intention to Mobile Social Network there is no research on this issue in the Ghanaian context.

This endeavoured to study fills this knowledge gap by seeking to identify the factors affecting users' intention to continue using Mobile Social Networks, and to analyse the relationships between these factors. We incorporated perceived enjoyment, perceived risk and privacy concern into the Expectancy Confirmation Theory of IS continuance. Results of this study extends the literature on continuance in the Mobile Social Network environment.

In the next section we presents a review of previous literature related to continuance usage of mobile social network and our proposed research model. In Section 3, the research methodology used for the study is described. The 
results of structural equation modelling (SEM) are presented in Section 4. Section 5 discusses the results of our study and highlights some theoretical and practical implications of our findings. We also identify some limitations of this study and provide directions for future research.

\section{Theoretical Background/Concepts and Hypotheses Development}

\subsection{Theory of Reasoned Action (TRA)}

The theory of reasoned action is one of the earliest theories applied to information systems adoption and has enjoyed prominence in academic literature. The theory was originally developed in 1967 but popularised by Ajzen \& Fishbein, (1980). According to the theory a person's behaviour has two motivational components. First one's attitude towards performing the behaviour and their concern about what other people who matter to them would think about that behaviour (Social Norm). Ajzen \& Fishbein (1980) observed that a person's intention to perform a behaviour was the only antecedent of the actual performance of the said behaviour. They also noted that behavioural intention was jointly determined by attitude and social norms.

Attitude represents a person's positive or negative feelings toward performing the said behaviour and is formed after an assessment of the consequences and the impact of the consequences of performing the said behaviour. Subjective norm on the other hand is a person's perception that people who are important to him/her think he/she should or should not perform that action (Ajzen \& Fishbein, 1980). A pictorial view of the model is presented in Figure 1.

$$
\mathbf{B I}=\mathbf{A}+\mathbf{S N}
$$

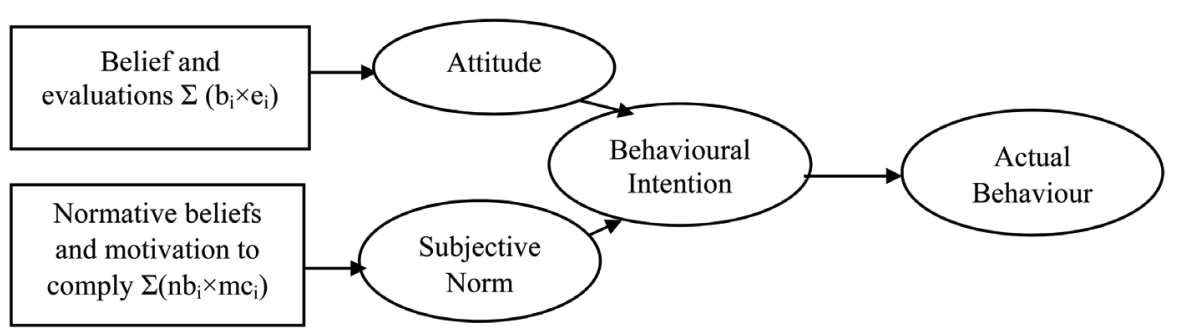

Figure 1 Theory of reasoned action (TRA) (Ajzen and Fishbein, 1980). 


\subsection{Technology Acceptance Model (TAM)}

The Technology Acceptance Model (TAM) proposed by Davis (1989) was deduced from the Theory of Reasoned Action (TRA). Though TRA remains a general theory to clarify general human conduct, TAM is particularly suited for information system usage. TAM was initially created to comprehend the causal connection between outer variables and client acknowledgment of PCbased applications. TAM has been generally utilized as a hypothetical system as a part of the late studies to clarify technology acceptance (Moon and Kim, 2001; Gillenson and Sherrell, 2002; Koufaris, 2002; McCloskey, 2004; Chen).

As exhibited in Figure 2, the model sets that genuine utilization is controlled by user behavioural intention to use (BIU), which is impacted by their attitude (A) and the conviction of perceived usefulness (PU). Users attitude, which reflects positive or unfavourable emotions towards utilizing the IS framework, is resolved mutually by perceived usefulness (PU) and perceived ease of use (PEOU). PU, thus, is impacted by PEOU and external variables. The external variables may incorporate system design elements, preparing, documentation and client support, and so on. The rationale innate in the TAM is that the easier mastery of the technology, the more helpful it is seen to be, in this way prompting more inspirational demeanour and more positive attitude and greater intention towards utilizing the technology and thus ensuring more prominent use of the technology.

\subsection{Expectation Confirmation Model of Information Systems Continuance (ECM-IS)}

Bhattacherjee (2001) extended the work on Expectation (Dis)confirmation Theory (ECT) (Oliver \& Burke, 1999; Oliver, 1999; Oliver \& Linda, 1981; Oliver, 1980) to study information systems, specifically online banking consumers continuance behave. He likened IS continuance decision in the

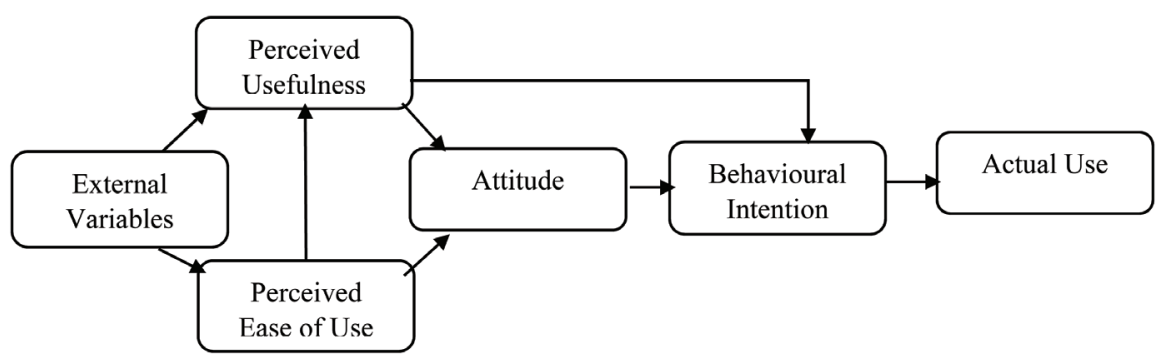

Figure 2 Technological acceptance model (TAM), (Davis, 1989). 
ECM-IS to repurchase decisions of consumers in the ECT because both decisions follow the sequences of (1) making initial adoption/acceptance or purchase decision, (2) initially using the product/service and (3) making expost decision to continue or reverse the initial decision. The model proposes that a user's satisfaction derived from the user of an IS product/service leads to its continuance use. Satisfaction is the ex-post evaluation of the user's initial experience represented by a positive feeling, indifference or negative feeling. According to Bhattacherjee (2001) a user's satisfaction with information system (IS) is dependent on the extent to which their initial expectations of the performance of the IS is confirmed (disconfirmed) during actual use. He proposed that satisfaction is predicted by perceived usefulness and confirmation. Perceived usefulness is the user's perception of the benefits they expect to derive from using the system and confirmation is the congruence between how the user expects the system to perform and how it actually performs. (Bhattacherjee, 2001).

\subsection{Privacy Concern}

Privacy concerns reflects a user's perception of how their personal information is being used. Social media network service providers collect information concerning users. They also hold information on the users' interactions with other users. Users of social networks may be concerned about how providers may collect store and use their personal information. If users feel that this information may leaked or that they can be tracked due to a privacy violation then, they may be reluctant to use the system. Users with high privacy concerns are of the opinion that giving up their personal information may result in some privacy risk to them. It may require greater levels of trust in the system to have these users adopt the system. Privacy concern has been found to directly affect behavioural intentions of users in different contexts (Akhter, 2014; Arpaci, Kilicer, \& Bardakci, 2015; Bansal, Zahedi, \& Gefen, 2010; Gao, Waechter, \& Bai, 2015; Li, 2014; McCole, Ramsey, \& Williams, 2010; Zhou \& Li, 2014; Zhou, 2011a). Aside the direct effect that privacy concern has on user behaviour, it has be shown to have indirect effects on user behaviour through the mediating roles of trust, perceived risk and perceived usefulness (Gashami, Chang, Rho, \& Park, 2015).

\subsection{Hypotheses Development}

Perceived Ease of Use (PEOU): The degree to which a person believes that using a particular system would be free from effort (Davis, 1989). Davis 
(1989) argued that the usefulness of a technology is dependent on how easy it is to use. In other words the easier it is for a user to interact with mobile social networks the more useful users would perceive it to be. The causal link between perceived ease of use and perceived usefulness has been tested and validated by previous researchers (Jongchul \& Sung-Joon, 2014; Park, Rhoads, Hou, \& Lee, 2014; Terzis, Moridis, \& Economides, 2013). We therefore posit that:

$\mathrm{H}_{1 \mathrm{a}}$ : Perceived Ease of Use positively affects Perceived Usefulness.

$\mathrm{H}_{1 \mathrm{~b}}$ : Perceived Ease of Use positively affects Satisfaction

Perceived Usefulness (PU): The salient belief that the degree to which a person uses a particular system would enhance his or her job performance (Davis, 1989). According to Burke (1997), perceived usefulness is the primary prerequisite for mass market technology acceptance, which solely depends on consumers' expectations about how technology can improve and simplify their lives. The expectation confirmation model of IS continuance also posits that when the system performs to the expectations of users they tend to get satisfied and in turn continue to use the IS (Bhattacherjee, 2001). Mobile social networks enable users to interact and share experiences with others anywhere and at any time. Users whose expectations about the performance of mobile social media are met are expected to be satisfied leading to their continuance use. Based on the above arguments we propose the following hypothesis:

$\mathrm{H}_{2}$ : Perceived Usefulness positively affects Satisfaction

Perceived Enjoyment (ENJ): Zhou (2011b) and Moon \& Kim (2001) view perceived enjoyment as an intrinsic source of motivation, referring to the degree of pleasure derived from using the system. When users adopt mobile social networks they expect to enjoy the service. As these expectations are met they tend to get satisfied with the service (Zhou, 2011b). The effect of perceived enjoyment on user behaviour has been studied extensively and has been supported (Cheng, 2012; Jongchul \& Sung-Joon, 2014; Koufaris, 2002; Zhou, 2011b). In line with the above literature we propose the following hypothesis:

$\mathrm{H}_{3}$ : Perceived Enjoyment positively affects Satisfaction

Perceived Risk (PR): The spatio-temporal nature of mobile applications and the unpredictability of the Internet infrastructure give rise to an implicit uncertainty with internet based systems (Pavlou, 2003). Various forms of risk exist in internet systems such as time risks, performance risk, privacy risk, financial risk, etc. In mobile social network, users have to contend with the risk 
of losing personal information either voluntarily or involuntarily due to theft. In this research we are concerned with privacy risk such as the risk of losing personal information shared with friends and the uncertainty associated with disclosing personal information to the service provider. We expect that users with high perceptions of privacy risk will feel lack of control and therefore would not be satisfied with the service and would not want to continue using it. We go forward to propose the following hypotheses:

$\mathrm{H}_{4 \mathrm{a}}$ : Perceived Risk negatively affects Satisfaction

$\mathrm{H}_{4 \mathrm{~b}}$ : Perceived Risk negatively affects Continuance Intention

Privacy Concerns (PRC): Privacy is the ability of an individual or group to seclude themselves or information about themselves and thereby reveal themselves selectively. The advent of the Web 2.0 has caused social profiling and is a growing concern for internet privacy. Concerns about ones' privacy refers to his/her concern that his/her privacy may be compromised (Zhou, 2011a). Privacy concern has been identified to have a direct significant effect on behavioural intention (Bansal et al., 2010; Gashami et al., 2015; Liu, Marchewka, Lu, \& Yu, 2005). Privacy concern has also been seen to have indirect effects on behavioural intention through trust (Bansal et al., 2010; Gashami et al., 2015; Liu et al., 2005; Zhou, 2011a), perceived risk (Slyke, Shim, Johnson, \& Jiang, 2006; Zhou \& Li, 2014) and perceived usefulness (Kumar, Mohan, \& Holowczak, 2008). In line with the expectancy theory users will disclose their personal information if they think the benefit associated with disclosure is greater than the risk (Culnan \& Bies, 2003). From the above literature we expect that privacy concern will have an effect on perceived risk, satisfaction and continuance intention. Based on the above arguments we posit that:

$\mathrm{H}_{5 \mathrm{a}}$ : Privacy Concerns positively affect Perceived Risk

$\mathrm{H}_{5 \mathrm{~b}}$ : Privacy Concerns negatively affects Satisfaction

$\mathrm{H}_{5 \mathrm{c}}$ : Privacy Concerns negatively affects Continuance Intention

Satisfaction: Satisfaction represents an amassed feeling developed with multiple interactions. As indicated by the expectation confirmation theory, satisfaction is a strong predictor of continuance intention (Bhattacherjee, 2001). The impact of satisfaction on user behaviour has been bolstered in various studies (Gao \& Bai, 2014; Kuo, Wu, \& Deng, 2009; Lin, 2012; Zhou, 2011b). We therefore posit that:

$\mathrm{H}_{6}$ : Satisfaction positively affects Continuance Intention 


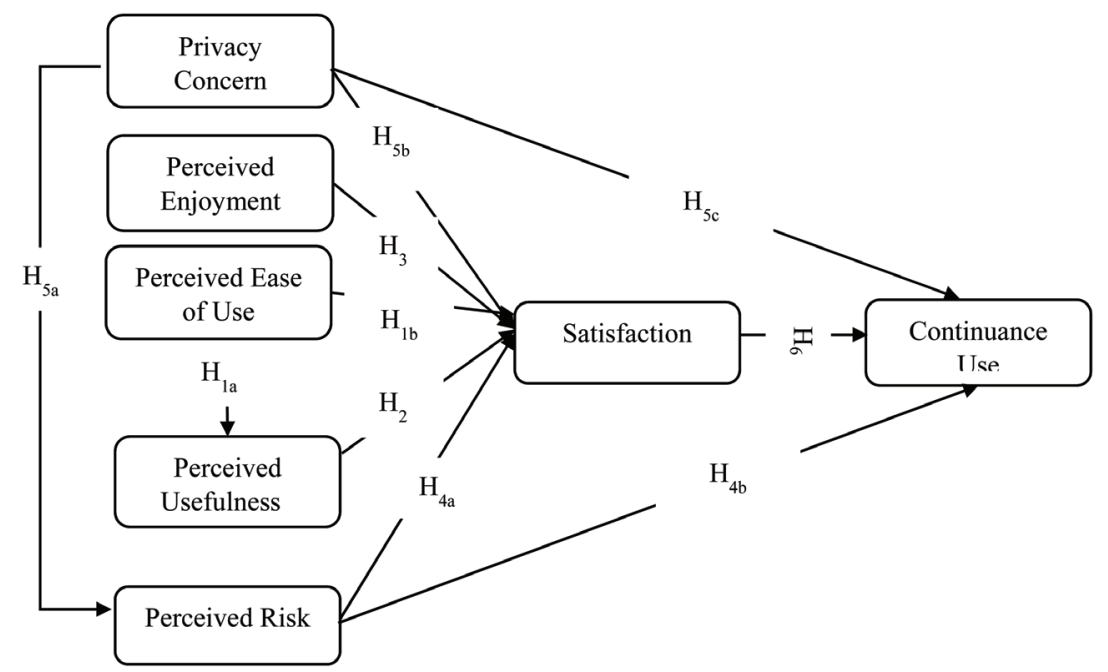

Figure 3 Research model.

\section{Methodology}

The measurement items for the latent variables used in this study were drawn from previous studies and the questions were reworded to fit the Mobile Social Network context. Perceived Usefulness and Perceived ease of use were from the Technology Acceptance Model, Satisfaction and Continuance from the ECM-IS model (Bhattacherjee, 2001), Perceived Enjoyment (Koufaris, 2002), Perceived Risk (Zhou, 2011a) and Privacy Concerns (Casaló, Flavián, \& Guinalíu, 2007; Zhao, Koenig-Lewis, Hanmer-Lloyd, \& Ward, 2010). Our measurement instrument had 23 items in all and items were presented in English and measured using a 5-point Likert scale anchored between 1 (Strongly Disagree) and 5 (Strongly Agree). Survey data was collected using paper-based questionnaires from 262 students in Ghana Technology University College and analysed using the PLS approach to Structural Equation Modelling with the use of SmartPLS software.

\section{Results}

\subsection{Measurement Model}

Results for the measurement model is presented in Tables 1 and 2. The measurement model is assessed based on reliability, convergent validity and discriminant validity. In evaluating indicator reliability the factor loadings of 
Factors Influencing the Continuance Use of Mobile Social Media

113

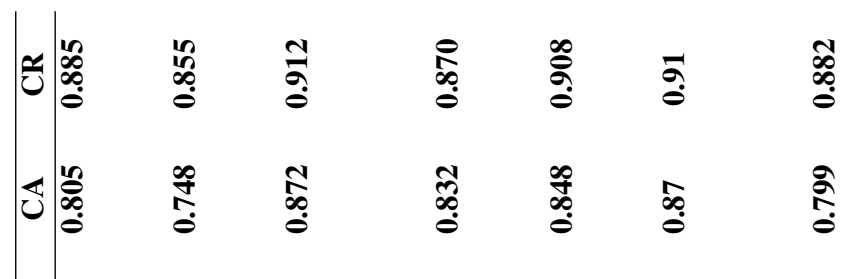

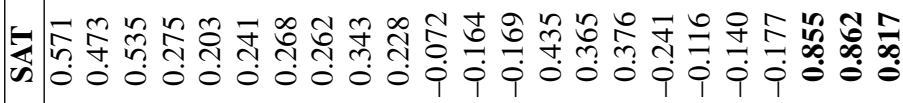

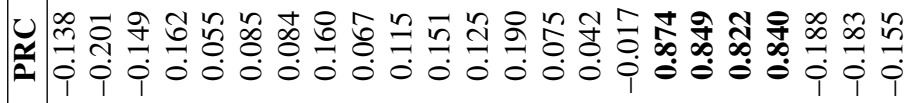

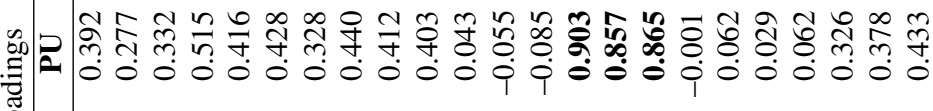

苟

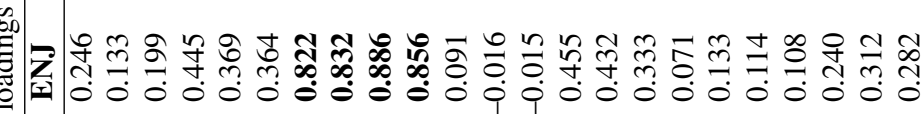

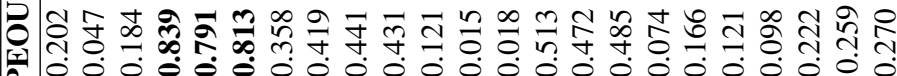

तั

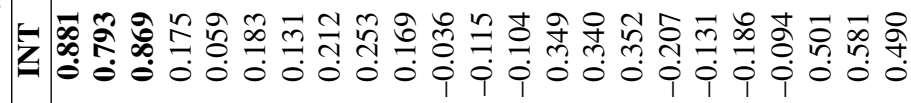

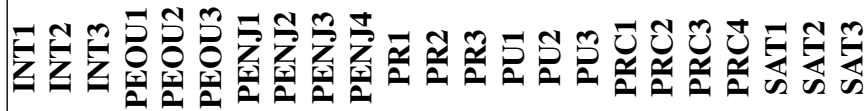

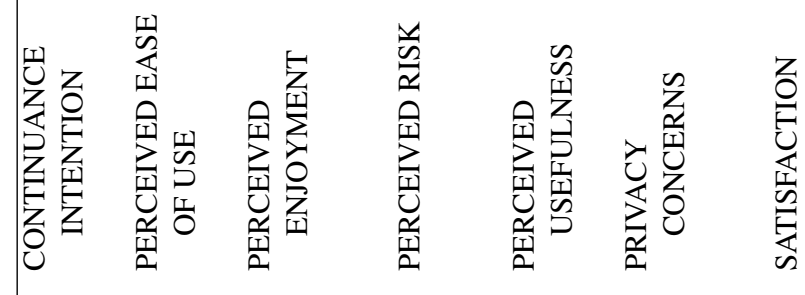


Table 2 Correlation matrix with square root of AVE

\begin{tabular}{lrrrrrrrr}
\hline & \multicolumn{1}{c}{ INT } & PEOU & ENJ & PR & PU & PRC & SAT & \multicolumn{1}{c}{ AVE } \\
\hline INT & $\mathbf{0 . 8 4 8}$ & & & & & & & $\mathbf{0 . 7 2 0}$ \\
PEOU & 0.175 & $\mathbf{0 . 8 1 4}$ & & & & & & $\mathbf{0 . 6 6 3}$ \\
ENJ & 0.230 & 0.486 & $\mathbf{0 . 8 4 9}$ & & & & & $\mathbf{0 . 7 2 2}$ \\
PR & -0.105 & 0.048 & 0.012 & $\mathbf{0 . 8 6 3}$ & & & & $\mathbf{0 . 7 4 4}$ \\
PU & 0.396 & 0.560 & 0.466 & -0.050 & $\mathbf{0 . 8 7 6}$ & & & $\mathbf{0 . 7 6 7}$ \\
PRC & -0.189 & 0.129 & 0.121 & 0.182 & 0.040 & $\mathbf{0 . 8 4 6}$ & & $\mathbf{0 . 7 1 6}$ \\
SAT & 0.623 & 0.297 & 0.331 & -0.166 & 0.449 & -0.208 & $\mathbf{0 . 8 4 5}$ & $\mathbf{0 . 7 1 2}$ \\
\hline
\end{tabular}

Note: Square roots of average variances extracted (AVEs) shown on diagonal

each indicator should be above 0.708 (Hair, Hult, Ringle, \& Sarstedt, 2014). Indicator reliability was achieved since all factor loadings from Table 1 were above the threshold. Construct Reliability was also assessed using Cronbach's alpha and Composite Reliability. For constructs to be reliable Cronbach's alpha and Composite Reliability values should be greater than 0.7 (Hair et al., 2014; Nunnally \& Bernstein, 1994). From Table 1 it is evident that all construct had Cronbach's alpha and Composite Reliabilities greater than 0.7, indicative of construct reliability. From Table 2 it can also be seen that the square root of the AVEs are greater than the cross correlations indicating that discriminant validity was satisfied.

Results from the analysis also showed that the factor loadings for each item is greater than the cross-loadings further providing support for discriminant validity. The Average Variance Extracted for each variable was above the threshold of 0.5 hence convergent validity was satisfied. Since the results from the analysis indicate that the constructs show sufficient levels of reliability, convergent validity and discriminant validity, a Structural Model was developed for further testing.

\subsection{Structural Model Assessment}

Results for structural model analysis are presented in Table 3. Perceived Ease of use was found to be a significant predictor of Perceived Usefulness ( $\beta=0.560, \mathrm{P}=0.000$ ) providing support for $\mathrm{H}_{1 \mathrm{a}}$. Perceived Ease of Use was however found not to be directly affecting Satisfaction. Rather, it had an indirect effect on satisfaction through the mediating role of Perceived Usefulness. Perceived Usefulness $(\beta=0.340, P=0.000)$, Perceived Enjoyment ( $\beta=0.174, \mathrm{P}=0.009)$, Perceived Risk $(\beta=-0.112, \mathrm{P}=0.078)$ and Privacy Concern $(\beta=-0.229, \mathrm{P}=0.000)$ were also found to be significant predictors of Satisfaction providing support for $\mathrm{H}_{2}, \mathrm{H}_{3}, \mathrm{H}_{4 a}$ and $\mathrm{H}_{5 \mathrm{~b}}$ respectively. 
Together they accounted for $29.3 \%$ of the variance in Satisfaction. Satisfaction $(\beta=0.611, \mathrm{P}=0.000)$ was also found to be a strong predictor of Continuance Intention. Privacy Concern and Perceived Risk were found not to directly affect Continuance Intention but indirectly through the

Table 3 Result for hypotheses testing

\begin{tabular}{|c|c|c|c|c|c|}
\hline Hypotheses & $\begin{array}{l}\text { Hypothesized } \\
\text { Path }\end{array}$ & $\begin{array}{c}\text { Path } \\
\text { Coefficient }\end{array}$ & T Statistics & P Values & Result \\
\hline $\mathrm{H}_{1 \mathrm{a}}$ & $\mathrm{PEOU} \rightarrow \mathrm{PU}$ & 0.560 & 7.937 & 0.000 & Supported \\
\hline $\mathrm{H}_{1 \mathrm{~b}}$ & $\mathrm{PEOU} \rightarrow \mathrm{SAT}$ & 0.057 & 0.724 & 0.469 & Not Supported \\
\hline $\mathrm{H}_{2}$ & $\mathrm{PU} \rightarrow \mathrm{SAT}$ & 0.340 & 3.854 & 0.000 & Supported \\
\hline $\mathrm{H}_{3}$ & $\mathrm{ENJ} \rightarrow \mathrm{SAT}$ & 0.174 & 2.631 & 0.009 & Supported \\
\hline $\mathrm{H}_{4 \mathrm{a}}$ & $\mathrm{PR} \rightarrow \mathrm{SAT}$ & -0.112 & 1.768 & 0.078 & Supported \\
\hline $\mathrm{H}_{4 \mathrm{~b}}$ & $\mathrm{PR} \rightarrow \mathrm{INT}$ & 0.008 & 0.169 & 0.866 & Not Supported \\
\hline $\mathrm{H}_{5 \mathrm{a}}$ & $\mathrm{PRC} \rightarrow \mathrm{PR}$ & 0.182 & 2.684 & 0.008 & Supported \\
\hline $\mathrm{H}_{5 b}$ & $\mathrm{PRC} \rightarrow \mathrm{SAT}$ & -0.229 & 4.297 & 0.00 & Supported \\
\hline $\mathrm{H}_{5 \mathrm{c}}$ & $\mathrm{PRC} \rightarrow \mathrm{INT}$ & -0.064 & 1.185 & 0.237 & Not Supported \\
\hline $\mathrm{H}_{6}$ & $\mathrm{SAT} \rightarrow \mathrm{INT}$ & 0.611 & 9.509 & 0.000 & Supported \\
\hline
\end{tabular}

$*$ Significant at $=0.1, * *$ Significant at $=0.05, * * *$ Significant at $=0.01$

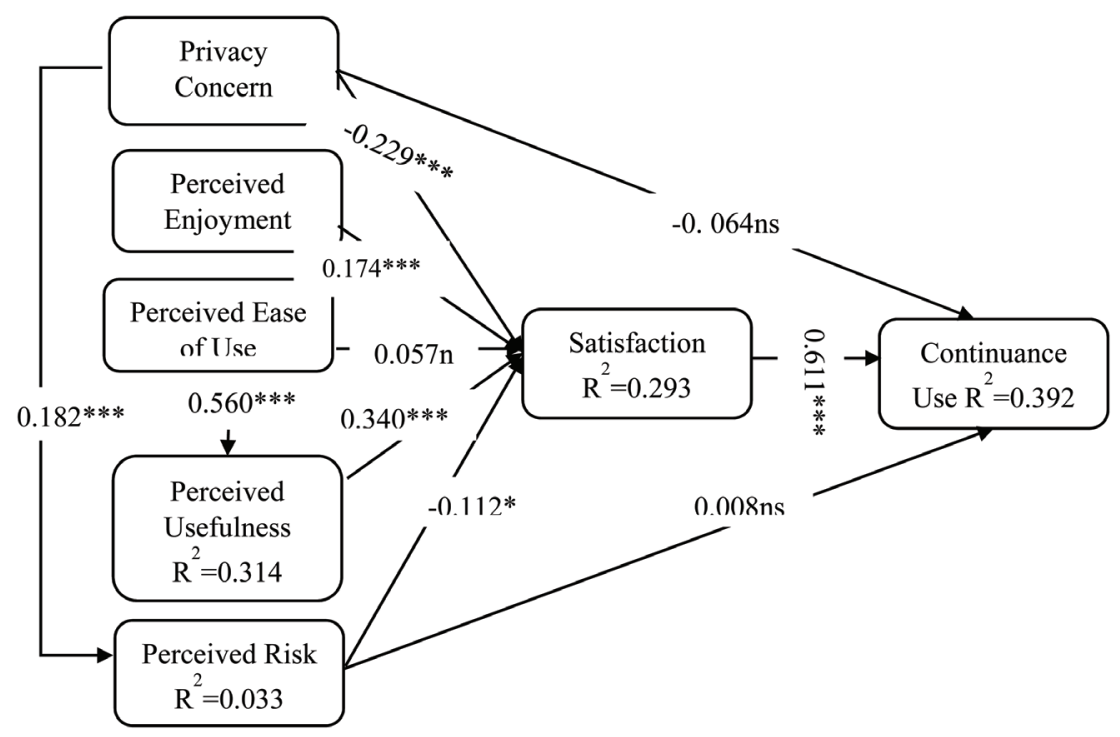

$*$ Significant at $=0.1, * *$ Significant at $=0.05, * * *$ Significant at $=0.01$

Figure 4 PLS results for structural model. 
mediating role of Satisfaction. About $40 \%$ of the variation in Continuance intention is accounted for by our model. Privacy Concern was also seen to have a significant effect on Perceived Risk.

Structural equation modelling was used to examine ten (10) hypotheses proposed for the study and as indicated in Table 3, with the exception if $\mathrm{H}_{1 \mathrm{~b}}$, $\mathrm{H}_{4 \mathrm{~b}}$ and $\mathrm{H}_{5 \mathrm{c}}$, all the other hypotheses were supported. Properties of the causal paths, including standardized path coefficients and hypotheses testing results in the hypothesized model are presented in Table 3.

\section{Discussions}

Mobile Social Networks are gaining popularity among mobile users because of the ubiquitous presence it offers users. The speedy growth in the number of users currently using Mobile Social Network has necessitated research in the adoption and continuance intentions of customers.

In this research we sought to examine the factors that affect continuance intention of Mobile Social Network users by integrating constructs from the Expectancy Confirmation Model of IS continuance with perceived risk, privacy concerns, and perceived enjoyment. Our results provide insight into the relationship between continuance intention and its antecedents and offer two contributions. (1) User satisfaction with Mobile Social Networks is derived from perceived usefulness, perceived risk, perceived enjoyment and privacy concerns. (2) Users' continuance intentions is derived only from satisfaction, supporting the work of (Bhattacherjee, 2001).

In line with previous studies of our results indicate that Perceived Usefulness has significant influence on Satisfaction (Bhattacherjee, 2001; Kim, 2011). Perceived Ease of Use was also found to have significant impact on Perceived Usefulness providing support for (Lim, Al-Aali, Heinrichs, \& Lim, 2013). Perceived Ease of Use had no significant impact on Satisfaction, this could probably be due to the fact that our sample consisted of young university students, most of whom are technology savvy. Perceived Enjoyment was also found to significantly predict Satisfaction corroborating previous studies (Jongchul \& Sung-Joon, 2014; Zhou, 2011b). Mobile social networks have a variety of entertaining services such sharing videos and pictures. Users adopt mobile social media networks to interact with others and also to derive some enjoyment. From the results we can infer that as expectations of enjoyment is fulfilled they would become satisfied and continue to use the service.As expected we also found negative relationships between Perceived Risk, Privacy Concerns and Satisfaction. Implying that as users became aware 
of the privacy risks associated with social media network they were less likely to be satisfied.

Users provide a lot of personal information when they register on the social media network. Further, as they use the service, they post and share a lot of personal information which may be kept on the servers of the service providers. Some social networking apps can also collect location information from users to provide them location-based services. When users have the impression that these information may not be handled properly they may choose not to continue using the service. Service providers could post their privacy policy as this has been seen to engender trust in the service and reduce privacy concerns (Wu, Huang, Yen, \& Popova, 2012).

Interestingly both perceived risk and privacy concern did not have any significant direct effect on continuance intention. However, through the mediating role of satisfaction both variables were seen to have an indirect effect on continuance intention. In line with previous studied we found a strong relationship between satisfaction and continuance intention (Bhattacherjee, 2001; Yoon \& Roland, 2015; Yuan, Liu, Yao, \& Liu, 2014).

\subsection{Implications}

From a theoretical standpoint, this study integrates the IS Continuance model with Privacy Concern, Perceived Enjoyment and Perceived Risk to explore the continuance use of mobile social networks. Previous works have concentrated on user adoption, but as noted earlier to ensure the sustenance of these social network provider, users must continue using the service. Also, extant research has focused on continuance use of social networks in the western world. However, not much has been done in the Ghanaian context. Our work therefore extends knowledge in continuance usage of IS services. Our results indicate that Privacy Concern has a significant negative effect on User Satisfaction. Perceive Usefulness, Perceive Enjoyment and Perceived Risk were also found to be significant in prediction Satisfaction.

From a practical perspective, the results imply that mobile social network service providers need to consider Privacy Concern, Perceived Enjoyment Perceived Risk and Perceived Usefulness if they want to make their users satisfied. This would ultimately lead to their continued use of the system. Also, since Privacy Concern was seen to have a strong negative influence on satisfaction service providers must adopt measures such as privacy policies and seals to lower the privacy concerns of users. They could also use reputation to engender trust and reduce privacy risk. Contrary to expectation and prior 
research Perceived Risk and Privacy Concerns did not have significant direct effects on Continuance Use but had indirect effect through satisfaction.

\subsection{Limitation and Direction for Future Research}

Even though the study found some interesting result that confirm previous studies a few limitations have to be considered when interpreting and generalizing results to other social media technologies and other countries. First the study collected data from university students and not the wider population. Although research has identified students as a representable part of the population, in the future researchers can consider using a different sample to re-test/validate the research model. Secondly the study did not consider the influence of demographic variables like age, gender, educational status, etc. In other studies these variables have been found to moderate relationship between factors that influence continuance. It would therefore be interesting to explore their effects. Finally our study used a cross-sectional design and since user behaviour is dynamic it would be exciting to consider a longitudinal design in future studies.

\section{References}

[1] Ajzen, I., \& Fishbein, M. (1980). Understanding attitudes and predicting social behavior. Englewood Cliffs NY Prentice Hall

[2] Akhter, S. H. (2014). Privacy concern and online transactions: The impact of internet self-efficacy and internet involvement. Journal of Consumer Marketing, 31(2), 118-125. http://doi.org/10.1108/JCM-062013-0606

[3] Arpaci, I., Kilicer, K., \& Bardakci, S. (2015). Effects of security and privacy concerns on educational use of cloud services. Computers in Human Behavior, 45, 93-98. http://doi.org/10.1016/j.chb.2014.11.075

[4] Bansal, G., Zahedi, F. "Mariam," \& Gefen, D. (2010). The impact of personal dispositions on information sensitivity, privacy concern and trust in disclosing health information online. Decision Support Systems, 49(2), 138-150. http://doi.org/10.1016/j.dss.2010.01.010

[5] Bhattacherjee, A. (2001). Understanding information system continuance: An Expectation confirmation model. MIS Quarterly, 25(3), 351-370. 
[6] Burke, R. R. (1997). Do You See What I See? The Future of Virtual Shopping. Journal of the Academy of Marketing Science, 25(4), 352-360. http://doi.org/10.1177/0092070397254007

[7] Casaló, L. V., Flavián, C., \& Guinalíu, M. (2007). The role of security, privacy, usability and reputation in the development of online banking. Online Information Review, 31(5), 583-603. http://doi.org/10.1108/14684520710832315

[8] Cheng, Y. (2012). Effects of quality antecedents on e-learning acceptance. Internet Research, 22(3), 361-390. http://doi.org/10.1108/106622 41211235699

[9] Culnan, M. J., \& Bies, R. J. (2003). Consumer Privacy: Balancing Economic and Justice Considerations. Journal of Social Issues, 59(2), 323-342. http://doi.org/10.1111/1540-4560.00067

[10] Davis, F. D. (1989). Perceived usefulness, perceived ease of use, and user acceptance of information technology. MIS Quarterly, 13(3), 319-340. http://doi.org/10.2307/249008

[11] Gao, L., \& Bai, X. (2014). An empirical study on continuance intention of mobile social networking services. Asia Pacific Journal of Marketing and Logistics, 26(2), 168-189. http://doi.org/10.1108/APJML-07-20130086

[12] Gao, L., Waechter, K. A., \& Bai, X. (2015). Understanding consumers' continuance intention towards mobile purchase: A theoretical framework and empirical study - A case of China. Computers in Human Behavior, 53, 249-262. http://doi.org/10.1016/j.chb.2015.07.014

[13] Gashami, J. P. G., Chang, Y., Rho, J. J., \& Park, M.-C. (2015). Privacy concerns and benefits in SaaS adoption by individual users: A trade-off approach. Information Development, (5). http://doi.org/10.1177/02666 66915571428

[14] Hair, J. F. J., Hult, G. T. M., Ringle, C., \& Sarstedt, M. (2014). A Primer on Partial Least Squares Structural Equation Modeling (PLS-SEM). Thousand Oaks: Sage Publications. http://doi.org/10.1016/j.lrp.2013.01.002

[15] Jongchul, O., \& Sung-Joon, Y. (2014). Validation of Haptic Enabling Technology Acceptance Model (HE-TAM): Integration of IDT and TAM. Telematics and Informatics, 31(4), 585-596. http://doi.org/10.101 6/j.tele.2014.01.002

[16] Kim, B. (2011). Understanding Antecedents of Continuance Intention in Social-Networking Services. Cyberpsychology, Behavior, and Social Networking, 14(4), 199-205. http://doi.org/10.1089/cyber.2010.0009 
[17] Koufaris, M. (2002). Applying the Technology Acceptance Model and flow theory to online consumer behavior. Journal of Information Systems Research, 13(2), 205-223. http://doi.org/10.1287/isre.13.2.205.83

[18] Kumar, N., Mohan, K., \& Holowczak, R. (2008). Locking the door but leaving the computer vulnerable: Factors inhibiting home users' adoption of software firewalls. Decision Support Systems, 46(1), 254-264. http://doi.org/10.1016/j.dss.2008.06.010

[19] Kuo, Y. F., Wu, C. M., \& Deng, W. J. (2009). The relationships among service quality, perceived value, customer satisfaction, and postpurchase intention in mobile value-added services. Computers in Human Behavior, 25(4), 887-896. http://doi.org/10.1016/j.chb.2009.03.003

[20] Li, Y. (2014). The impact of disposition to privacy, website reputation and website familiarity on information privacy concerns. Decision Support Systems, 57(1), 343-354. http://doi.org/10.1016/j.dss.2013.09.018

[21] Lim, J.-S., Al-Aali, A., Heinrichs, J. H., \& Lim, K.-S. (2013). Testing alternative models of individuals' social media involvement and satisfaction. Computers in Human Behavior, 29(6), 2816-2828. http://doi.org/10.1016/j.chb.2013.07.022

[22] Lin, W. S. (2012). Perceived fit and satisfaction on web learning performance: IS continuance intention and task-technology fit perspectives. International Journal of Human Computer Studies, 70(7), 498-507. http://doi.org/10.1016/j.ijhcs.2012.01.006

[23] Liu, C., Marchewka, J. T., Lu, J., \& Yu, C.-S. (2005). Beyond concern-a privacy-trust-behavioral intention model of electronic commerce. Information \& Management, 42(2), 289-304. http://doi.org/10.1016/j.im. 2004.01.003

[24] McCole, P., Ramsey, E., \& Williams, J. (2010). Trust considerations on attitudes towards online purchasing: The moderating effect of privacy and security concerns. Journal of Business Research, 63(9-10), 1018-1024. http://doi.org/10.1016/j.jbusres.2009.02.025

[25] Moon, J. W., \& Kim, Y. G. (2001). Extending the TAM for a WorldWide-Web context. Information and Management, 38(4), 217-230. http://doi.org/10.1016/S0378-7206(00)00061-6

[26] Nunnally, J., \& Bernstein, I. (1994). Psychometric Theory (3rd ed.). New York: McGraw-Hill.

[27] Oliver, R. L. (1980). A Cognitive Model of the Antecedents and Consequences of Satisfaction Decisions. Journal of Marketing Research, 17(4), 460-469. 
[28] Oliver, R. L. (1999). Whence consumer loyalty? Journal of Marketing. Retrieved from http://search.ebscohost.com/login.aspx?direct=true\& profile $=$ ehost $\&$ scope $=$ site $\&$ authtype $=$ crawler $\&$ jrnl $=00222429 \& A N=24$ 44274\&h=gx910oLpWeEmSRwxdnVVTF0cZFXHLX\%2FfSknEYzpS VlrFtQSvbNOKhqnVEe\%2BLuhQgkQhS\%2B7CGZ418YniBvZ\%2Fl eg\%3D\%3D\&crl=c

[29] Oliver, R. L., \& Burke, R. R. (1999). Expectation Processes in Satisfaction Formation: A Field Study. Journal of Service Research. http://doi.org/10.1177/109467059913002

[30] Oliver, R. L., \& Linda, G. (1981). Effect of satisfaction and its antecedents on consumer preference and intention. Advances in Consumer Research, 8(1), 88-93.

[31] Park, N., Rhoads, M., Hou, J., \& Lee, K. M. (2014). Understanding the acceptance of teleconferencing systems among employees: An extension of the technology acceptance model. Computers in Human Behavior, 39, 118-127. http://doi.org/10.1016/j.chb.2014.05.048

[32] Pavlou, P. A. (2003). Consumer Acceptance of Electronic Commerce: Integrating Trust and Risk with the Technology Acceptance Model. International Journal of Electronic Commerce, 7(3), 34. http://doi.org/ 10.1080/10864415.2003.11044275

[33] Slyke, C. Van, Shim, J., Johnson, R., \& Jiang, J. (2006). Concern for Information Privacy and Online consumer purchasing. Journal of the Association for Information Systems, 7(6), 415-444. Retrieved from http://ais.bepress.com/cgi/viewcontent.cgi?article=1266\&context=jais

[34] Spiller, J., Vlasic, A., \& Yetton, P. (2007). Post-adoption behavior of users of Internet Service Providers. Information and Management, 44(6), 513-523. http://doi.org/10.1016/j.im.2007.01.003

[35] Terzis, V., Moridis, C. N., \& Economides, A. a. (2013). Continuance acceptance of computer based assessment through the integration of user's expectations and perceptions. Computers and Education, 62, 50-61. http://doi.org/10.1016/j.compedu.2012.10.018

[36] Vatanasombut, B., Igbaria, M., Stylianou, A. C., \& Rodgers, W. (2008). Information systems continuance intention of web-based applications customers: The case of online banking. Information and Management, 45(7), 419-428. http://doi.org/10.1016/j.im.2008.03.005

[37] Wu, K. W., Huang, S. Y., Yen, D. C., \& Popova, I. (2012). The effect of online privacy policy on consumer privacy concern and trust. Computers in Human Behavior, 28(3), 889-897. http://doi.org/10.1016/j.chb.2011. 12.008 


\section{K. S. Ofori et al.}

[38] Yoon, C., \& Roland, E. (2015). Understanding Continuance Use in Social Networking Services. Journal of Computer Information Systems, 55(2), 1-8.

[39] Yuan, S., Liu, Y., Yao, R., \& Liu, J. (2014). An investigation of users' continuance intention towards mobile banking in China. Information Development. http://doi.org/10.1177/0266666914522140

[40] Zhao, A. L., Koenig-Lewis, N., Hanmer-Lloyd, S., \& Ward, P. (2010). Adoption of internet banking services in China: Is it all about trust? International Journal of Bank Marketing, 28(1), 7-26. http://doi.org/10.1108/02652321011013562

[41] Zhou, T. (2011a). The impact of privacy concern on user adoption of location-based services. Industrial Management \& Data Systems, 111(2), 212-226. http://doi.org/10.1108/02635571111115146

[42] Zhou, T. (2011b). Understanding mobile Internet continuance usage from the perspectives of UTAUT and flow. Information Development, 27(3), 207-218. http://doi.org/10.1177/0266666911414596

[43] Zhou, T., \& Li, H. (2014). Understanding mobile SNS continuance usage in China from the perspectives of social influence and privacy concern. Computers in Human Behavior, 37, 283-289. http://doi.org/10.1016/j. chb.2014.05.008

\section{Biographies}

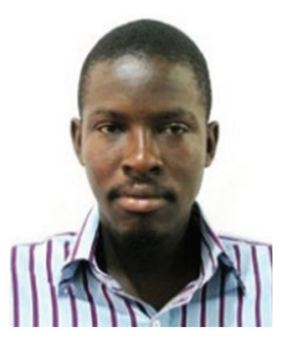

K. S. Ofori is a doctoral student at SMC University, Switzerland. He holds a Master of Science degree in Telecommunications Technology and a Postgraduate diploma in Business Administration. He is currently a lecturer in Information Security, Reliability Engineering and Data Communications. His research interests include PLS path modelling and technology adoption. Kwame can be reached at: kwamesimpe@gmail.com 


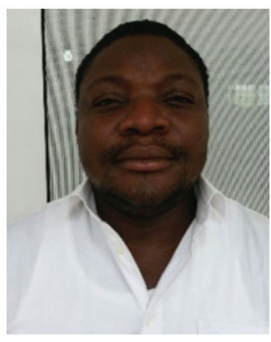

E. Fianu is a faculty member in the Informatics Faculty of Ghana Technology University College (GTUC). His areas of lecturing are Database Systems, Systems Analysis and Design, Computer applications for Management, and E-Commerce. Prior to joining GTUC, he worked with Vodafone Ghana for 11 years as a Customer Experience, Sales and Service Provisioning Manager. He holds a Master of Science degree in Management Information Systems from Coventry University, and a Bachelor of Science Degree in Agricultural Economics from the University of Ghana. His research interests include Artificial Neural Networks, Technology Adoption, and e-Learning. Eli can be reached at: efianu@gmail.com

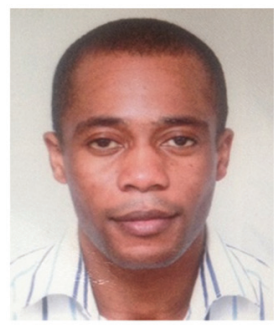

O. Larbi-Siaw is a rigorous problem solver, with a passion for designing systematic decision making systems. He is the Head of Department for Economics at Ghana Technology University College. His research interest is in the area of macroeconomics, innovation economics, game theory, artificial intelligence, digital analytics and finance. He is currently a $\mathrm{PhD}$ student at Swiss Management Center (SMC). Otu can be reached at: oLarbi-Siaw @ gtuc.edu.gh 


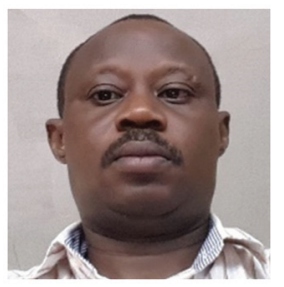

R. E. Gladjah is a lecturer in the Department of Mathematics and Statistics, Ho Polytechnic, Ghana. He had his first degree in Statistics and Economics from the University of Ghana and a Master of Science in Statistics from Regent University College of Science and Technology. He has seventeen years of teaching experience in Statistics and Computer Applications and specializes in Time Series, Multivariate and Categorical Data Analyses. His research interests include technology adoption and time series analysis. Eddie can be reached at: e1684@yahoo.com

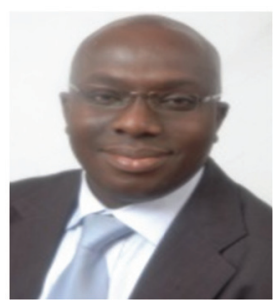

E. O. Yeboah-Boateng is a senior lecturer and the Head (acting Dean), Faculty of Informatics, at the Ghana Technology University College (GTUC), in Accra. Ezer is a Telecoms Engineer and an ICT Specialist; an executive with over 20 years of corporate experience and about 8 years in academia. He has over 10 peer-reviewed international journal papers to his credit. His research focuses on cyber-security vulnerabilities, digital forensics, cybercrime, cloud computing, Big data and fuzzy systems. He can be reached at: eyeboah-boateng@gtuc.edu.gh 